\title{
Time course of ventricular arrhythmias and the signal averaged electrocardiogram in the post- infarction period: a prospective study of correlation
}

\author{
GIOIA TURITTO, EDWARD B CAREF, GREGORY MACINA, JOHN M FONTAINE, \\ SHANTHA N URSELL, NABIL EL-SHERIF
}

From the State University of New York, Health Science Center and Veterans Administration Medical Center, Brooklyn, New York, USA

SUMMARY The incidence and time course of complex ventricular arrhythmias and of the abnormal signal averaged electrocardiogram were studied prospectively in 90 patients in the first two months after acute myocardial infarction. Serial recordings of both 24 hour ambulatory and signal averaged electrocardiograms were obtained 0-5 days (phase 1), 6-30 days (phase 2), and 31-60 days (phase 3) after infarction. A total of 264 ambulatory electrocardiograms and 264 signal averaged electrocardiograms were available for analysis. Complex ventricular arrhythmias were seen in $31 \%, 17 \%$, and $38 \%$ of patients during phases 1,2 , and 3 respectively, and abnormal signal averaged electrocardiogram in $13 \%, 24 \%$, and $16 \%$. The incidence of complex ventricular arrhythmias was not significantly different in patients with or without an abnormal signal averaged electrocardiogram in the entire study period nor in any of the three phases after infarction. During phase 2 when abnormal signal averaged electrocardiograms were most common complex ventricular arrhythmias were least common.

This lack of correlation suggests that the abnormal signal averaged electrocardiogram and complex ventricular arrhythmias after infarction have different electrophysiological bases.

Indices of left ventricular dysfunction ${ }^{1-4}$ and electrical instability ${ }^{35-9}$ are the strongest predictors of mortality after infarction. Three markers for electrical instability have commonly been investigated: (a) spontaneous ventricular arrhythmias during long term ambulatory electrocardiographic recording, ${ }^{1-35-7}(b)$ ventricular tachycardias induced by programmed electrical stimulation, ${ }^{18-11}$ and (c) late potentials detected on the signal averaged electrocardiogram..$^{91-14}$ The prognostic significance of arrhythmias elicited by programmed stimulation remains controversial. ${ }^{15}$ On the other hand, complex ventricular arrhythmias on the ambulatory electrocardiogram have shown independent correlation with sudden death in several large multicentre studies. ${ }^{237}$ The role of the signal averaged electrocardiogram for identifying patients at risk of sudden

Requests for reprints to Dr Gioia Turitto, State University of New York, Health Science Center, 450 Clarkson Avenue, Box 1199, Brooklyn, New York, USA.

Accepted for publication 8 March 1988 death after myocardial infarction has been recently emphasised. ${ }^{9111214}$

Most studies have analysed single recordings of the ambulatory and signal averaged electrocardiograms obtained at different times after infarction. We prospectively studied the correlation between the incidence and time course of complex ventricular arrhythmias and late potentials during the first two months after infarction by analysing serial records of the 24 hour ambulatory electrocardiogram and the signal averaged electrocardiogram.

\section{Patients and methods}

\section{PATIENTS}

The criteria for inclusion in the study were: $(a)$ a diagnosis of acute myocardial infarction, confirmed by clinical and electrocardiographic criteria and by an increase in serum concentrations of cardiac enzymes (creatine kinase MB); (b) the absence of bundle branch block on the standard electrocardiogram; (c) completion of the study. We studied 90 
patients (63 men and 27 women aged 30-81 (mean (SD) $59.2(13.4)$ ) between October 1985 and March 1987. Serial recordings were obtained in the first two months after infarction: (a) 0-5 days after infarction (phase 1); (b) 6-30 days after infarction (phase 2); (c) 31-60 days after infarction (phase 3 ). An ambulatory electrocardiogram and a signal averaged electrocardiogram were obtained within a 24 hour period during each of the three phases. Surviving patients had recordings during all three phases. The myocardial infarction was anterior in $54(60 \%)$ patients, inferior in $29(32 \%)$, and non Q-wave in seven $(8 \%)$. A previous myocardial infarction was suggested by history or electrocardiogram or both in $11(12 \%)$ patients.

\section{SIGNAL AVERAGED ELECTROCARDIOGRAM}

The signal averaged electrocardiogram was recorded with the Arrhythmia Research Technology model 101PCD electrocardiograph by methods described by Simson. ${ }^{16}$ The electrocardiogram was recorded during sinus rhythm with standard bipolar orthogonal X, Y, and Z leads. Signals were amplified, averaged, and filtered with a bidirectional filter at frequencies of $25-250 \mathrm{~Hz}$. The filtered leads were then combined into a vector magnitude $(\sqrt{ } \mathbf{X}+\mathrm{Y} 2+\mathrm{Z} 2)$. A computer program algorithm determined the onset and offset of the QRS complex and calculated the total filtered $Q R S$ duration and the root mean square voltage of the signals in the last $\mathbf{4 0}$ $\mathrm{ms}$ of the filtered QRS. The duration of low amplitude signals $<40 \mu \mathrm{V}$ was also calculated but was not used for analysis. Recordings with a noise level $\geqslant 1 \mu \mathrm{V}$ were rejected. A total of 264 signal averaged electrocardiograms with a mean (SD) noise level of $0.484(0.179) \mu \mathrm{V}$ were considered for analysis. Late potentials were defined as low amplitude signals in the last $40 \mathrm{~ms}$ of the filtered QRS with a root mean square voltage $\leqslant 25 \mu \mathrm{V}$. An abnormal signal averaged electrocardiogram was defined as a recording showing the presence of late potentials or a total filtered QRS duration $\geqslant 120 \mathrm{~ms}$ or both. ${ }^{16}$

\section{AMBULATORY ELECTROCARDIOGRAM}

A two channel, 24 hour electrocardiogram was recorded with the Avionics (model 445) portable units and analysed with the Avionics (model Evaluator II 9500A) replay unit. Arrhythmia detection was validated by one of the investigators. Complex ventricular arrhythmias were classified as frequent ventricular premature complexes ( $\geqslant 10 /$ hour); nonsustained ventricular tachycardia $(\geqslant 3$ ventricular premature complexes lasting $<30$ seconds at a rate $<100 / \mathrm{min}$ ); and sustained ventricular tachycardia (lasting $\geqslant 30 \mathrm{~s}$ ). The incidence of ventricular fibrilla- tion during the first five days after infarction was also $\frac{T}{\Phi}$ assessed and a correlation with the signal averaged electrocardiogram was sought.

STATISTICAL ANALYSIS

We used the $\chi^{2}$ test to analyse the incidence of complex ventricular arrhythmias in patients with or $\frac{\bar{F}}{\bar{N}}$ without an abnormal signal averaged electrocar- $\frac{N}{D}$ diogram. We used Yates' correction for continuity or $\stackrel{\mathbb{\Omega}}{\unrhd}$ Fisher's exact text when appropriate. ${ }^{17}$ A probability के (p) value $<0.05$ was considered to be statistically $\vec{\circ}$ significant.

\section{Results}

INCIDENCE OF ABNORMAL SIGNAL AVERAGED ELECTROCARDIOGRAMS AND COMPLEX VENTRICULAR ARRHYTHMIAS

Phase 1 (0-5 days after infarction)-The signal $\mathrm{O}$ averaged electrocardiogram and the 24 hour ambulatory electrocardiogram were obtained in all $c$ 90 patients enrolled in the study. The signal averaged electrocardiogram was abnormal in $12(13 \%) \overrightarrow{0}$ patients and complex ventricular arrhythmias were $\infty_{\infty}^{\infty}$ recorded during the ambulatory electrocardiogram in $28(31 \%)$ patients. The ambulatory electrocardiogram showed frequent ventricular premature complexes in $21(23 \%)$ patients, non-sustained ventricular tachycardia in $16(18 \%)$, and sustained ventricular tachycardia in one $(1 \%)$. On the other hand, ventricular fibrillation occurred in $7(8 \%) \overrightarrow{\overrightarrow{0}}$ patients, two with and five without complex ventricular arrhythmias on the ambulatory electrocardiogram. All episodes of ventricular fibrillation occurred within 48 hours of admission and car- $\vec{\nabla}$

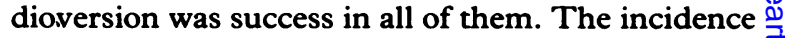
of complex ventricular arrhythmias on the $\frac{\dot{\sigma}}{\sigma}$ ambulatory electrocardiogram was not statistically different in patients with or without an abnormal $\delta$ signal averaged electrocardiogram $(50 v 28 \%)$. None of the patients who developed ventricular fibrillation had an abnormal signal averaged electrocardiogram. $D$ Phase 2 (6-30 days after infarction)-The signal averaged and 24-hour ambulatory electrocar- N diograms were obtained in 89 patients. One patient ${ }^{\text {or }}$ with an abnormal signal averaged electrocardiogram $N$ in phase 1 died of electromechanical dissociation as $\underset{\omega}{N}$ the terminal event in cardiogenic shock on the eighth day after infarction. The incidence of an abnormalo signal averaged electrocardiogram was higher in $\overparen{\mathbb{Q}}$ phase 2 than in phase 1 (21 cases, $\left(24^{\circ}{ }_{0}\right)$ ) whereas the $\stackrel{\odot}{?}$ incidence of complex ventricular arrhythmias on the ambulatory electrocardiogram was lower (15 cases, $\frac{0}{+}$ $\left.\left(17_{0}^{\circ}\right)\right)$. Frequent ventricular premature complexes $\overbrace{\mathbb{Q}}$ occurred in $12\left(13^{\circ}{ }_{0}\right)$ patients, non-sustained ven- $\stackrel{\mathbb{\triangle}}{\stackrel{\Omega}{\alpha}}$ tricular tachycardia in five $\left(6^{\circ}{ }_{0}\right)$, and sustained 


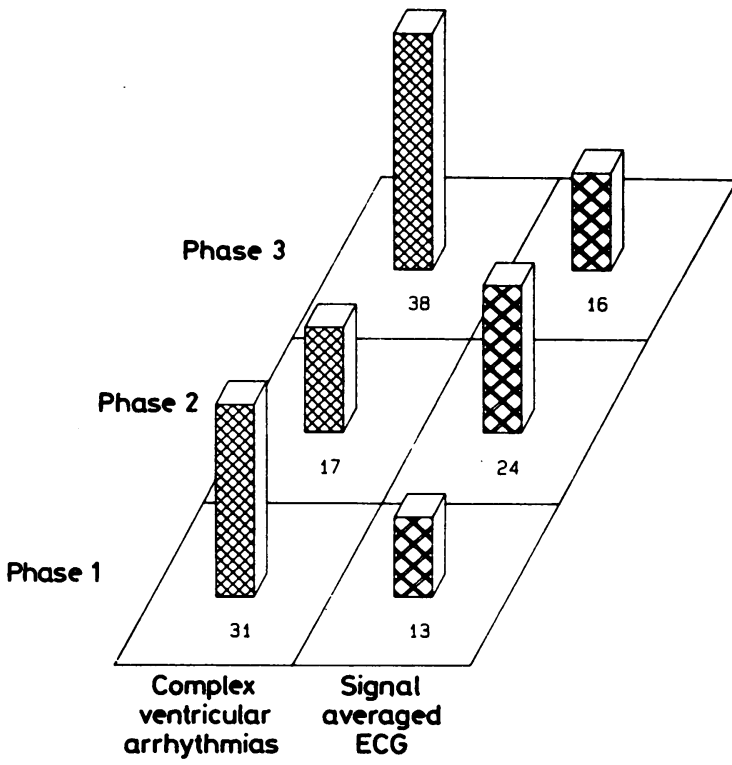

Fig 1 Frequency of complex ventricular arrhythmias and an abnormal signal averaged electrocardiogram in patients after acute myocardial infarction.

ventricular tachycardia in one $\left(1^{\circ}{ }_{0}\right)$. As in phase 1 , the incidence of complex ventricular arrhythmias was not statistically different in patients with or without an abnormal signal averaged electrocardiogram $\left(19^{\circ}{ }_{0} v 16^{\circ}{ }_{0}\right)$.

Phase 3 (31-60 days after infarction)-The signal averaged and 24 hour ambulatory electrocardiograms were recorded in 85 patients. There were four cardiac deaths: one was caused by incessant ventricular tachycardia in a patient with an abnormal signal averaged electrocardiogram and three were not sudden and occurred in two patients with and one patient without an abnormal signal averaged electrocardiogram. The incidence of an abnormal signal averaged electrocardiogram was lower than in phase 2 (14 cases, $\left(16^{\circ}{ }_{0}\right)$ ), while complex ventricular arrhythmias were more frequent on the ambulatory electrocardiogram (33 patients, $(38 \%)$ ). Frequent ventricular premature complexes occurred in 28 $\left(33^{\circ}{ }_{0}\right)$ patients, non-sustained ventricular tachycardia in $12\left(14^{\circ}, \mathrm{o}\right)$ patients, and sustained ventricular tachycardia in one $(1 \%)$ patient. As in phases 1 and 2 , the incidence of complex ventricular arrhthymias was not statistically different in patients with or without an abnormal signal averaged electrocardiogram $\left(57^{\circ}, v 35^{\circ} \%\right)$.

Figure 1 summarises the incidence of complex ventricular arrhythmias and an abnormal signal averaged electrocardiogram during the three postinfarction phases. The figure shows that complex
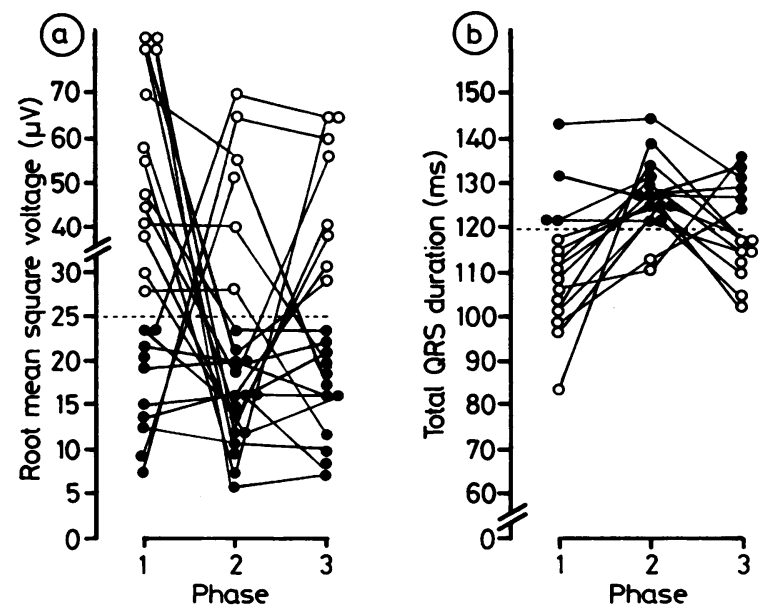

Fig 2 Variables measured on signal averaged electrocardiogram in the patients who had one or more abnormal recordings. Changes in the low amplitude signals in the last $40 \mathrm{~ms}$ of the filtered $Q R S$ complex (a) and in the total duration of the filtered $Q R S(b)$ in serial recordings obtained 0-5 days, 6-30 days, and 31 to 60 days after infarction are shown. The horizontal dashed lines indicate the criteria for an abnormal signal averaged electrocardiogram. See text for detail.

ventricular arrhythmias were common in the first five days after infarction, became less frequent between six and 30 days, and showed a late increase during the second month after myocardial infarction. Conversely, the incidence of an abnormal signal averaged electrocardiogram reached a maximum between six and 30 days after infarction.

\section{TIME COURSE OF THE ABNORMAL SIGNAL} AVERAGED ELECTROCARDIOGRAM

An abnormal signal averaged electrocardiogram was seen during one or more of the post-infarction phases in $28(31 \%)$ patients (a late potential $(n=13)$, a long filtered QRS $(n=5)$, or both $(n=10))$. The recording returned to normal in $42 \%$ of the patients within 60 days of infarction. An abnormal recording was more common in patients with inferior infarction

Table 1 Time course of the abnormal signal averaged electrocardiogram in acute myocardial infarction

\begin{tabular}{llll}
\hline Phase 1 & Phase 2 & Phase 3 & Number of patients (\%) \\
\hline Yes & Yes & Yes & $6(25)$ \\
Yes & Yes & No & $1(4)$ \\
Yes & No & No & $2(8)$ \\
No & Yes & Yes & $5(21)$ \\
No & Yes & No & $7(29)$ \\
No & No & Yes & $3(13)$ \\
\hline
\end{tabular}

Yes, signal averaged electrocardiogram abnormalities present; No, signal averaged electrocardiogram abnormalities absent. 
(14 (48\%) of 29 patients) than in those with anterior infarction (14 $(26 \%)$ of 54$)$. All five patients with a signal averaged electrocardiogram showing an abnormal QRS duration had anterior infarction. The evolution of abnormalities on the signal averaged electrocardiogram was investigated in 24 out of the 28 patients with an abnormal recording who underwent serial studies in all three post-infarction phases (fig 2). The table shows the results of this analysis. The number of abnormal signal averaged electrocardiograms was highest during phase 2 (19 cases). Fifty percent of the patients had only one abnormal recording (fig 3)-25\% had two abnormal recordings and $25 \%$ had abnormalities in all three signal averaged electrocardiograms.
CORRELATION BETWEEN THE AMBULATORY AND T SIGNAL AVERAGED ELECTROCARDIOGRAMS IN INFERIOR AND ANTERIOR MYOCARDIAL

INFARCTIONS diograms were more common in patients with inferior infarction than in those with anterior infarc 음. tion, we examined the correlation between abnorma $\frac{\text { s }}{5}$ signal averaged electrocardiogram and complex ven- $\Omega$ tricular arrhythmias separately in these two groups In patients with inferior infarction the incidence of complex ventricular arrhythmias was not statistically_ different in patients with or without an abnormat $\omega$ signal averaged electrocardiogram $(50 \%$ v $22 \%$ in phase $1,0 v 18 \%$ in phase $2,50 \% v 39 \%$ in phase 3$) \stackrel{?}{?}$

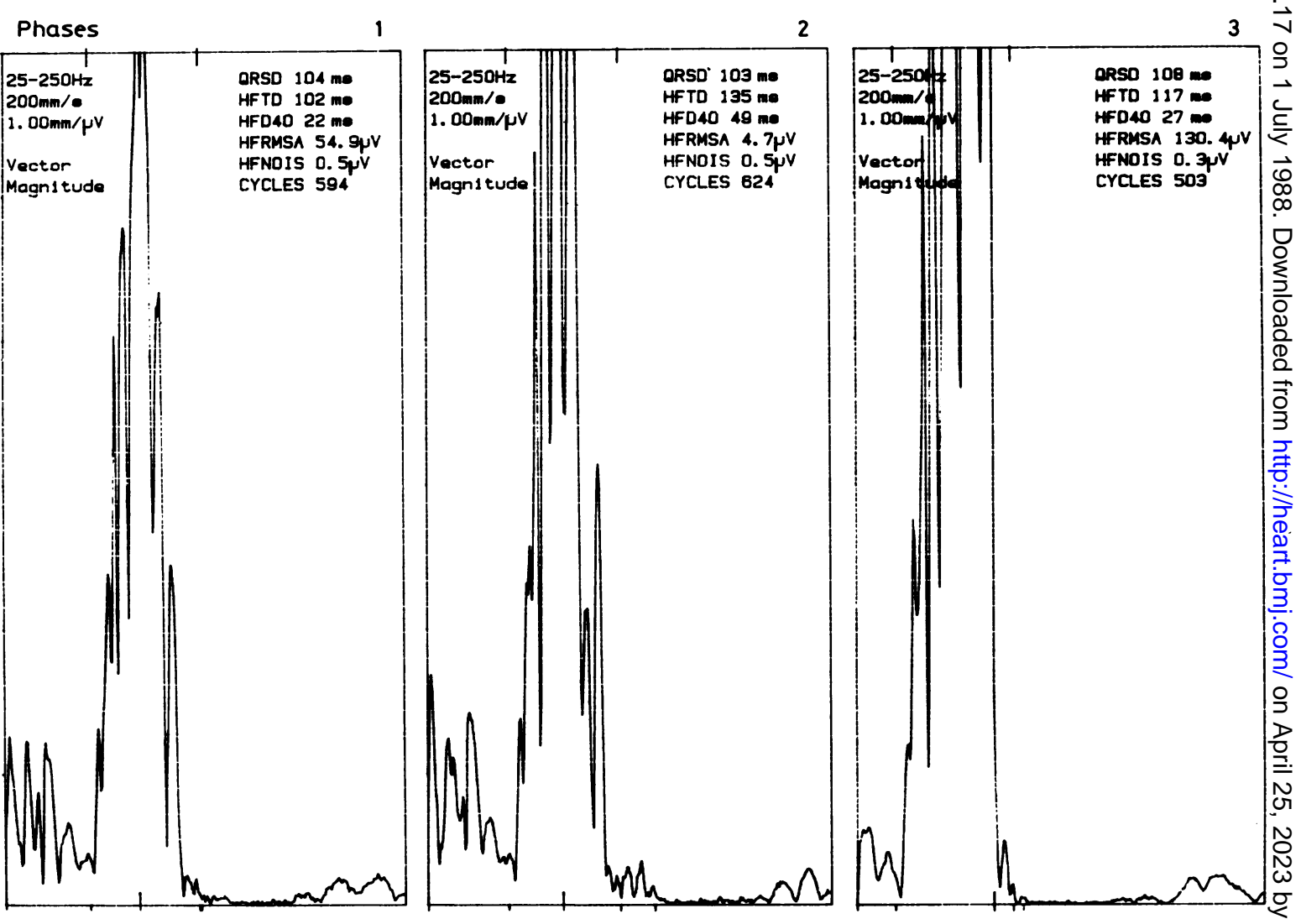

Fig 3 Time course of the signal averaged electrocardiogram in a patient with acute anterior wall myocardial infarction. The $\stackrel{0}{\subseteq}$ vector magnitude recordings of the filtered $Q R S$ complex are shown. The three recordings from left to right were obtained, 4 , 90 and 35 days after infarction respectively. Abnormalities in the signal averaged electrocardiogram were first seen in the record obtained nine days after infarction as a low amplitude signal in the last $40 \mathrm{~ms}$ of the filtered $Q R S$ of $4 \cdot 7 \mu V$ and a filtered $Q R S$ complex lasting $135 \mathrm{~ms}$. The recording became normal by the 35th day after infarction. $Q R S D, Q R S$ duration; HFTD high frequency total $Q R S$ duration; HFD40, duration of high frequency low amplitude signals $(<40 \mu V) ; H F R M S A$, high $\bigcirc$ frequency root mean square voltage of signals in the last $40 \mathrm{~ms}$ of the high frequency $Q R S ; H F N O I S$, high frequency noise level; Cycles, number of averaged $Q R S$ complexes. 
Similarly, in patients with anterior infarction the incidence of complex ventricular arrhythmias was not statistically different in patients with or without an abnormal signal averaged electrocardiogram $(50 \% v 31 \%$ in phase $1,40 \% v 16 \%$ in phase $2,67 \%$ $v 33 \%$ in phase 3 ).

\section{ANTIARRHYTHMIC DRUGS}

Exception for two patients who developed sustained ventricular tachycardia and were given a total of four different antiarrhthymic drugs, the only two antiarrhythmic agents that were used throughout the study were lignocaine and $\beta$ blockers. Lignocaine was given to seven patients for variable periods during their stay in the coronary care unit. The ambulatory and signal averaged electrocardiograms were always recorded while the patients were not receiving lignocaine. Thirty patients were given $\beta$ blocking drugs at the discretion of their attending physician during the study period. No attempt was made to obtain the recordings when these patients were not taking $\beta$ blocking drugs.

\section{CLINICAL OUTCOME}

There were five cardiac deaths during the study period; four were not sudden and the fifth was caused by incessant ventricular arrhythmia. An abnormal signals averaged electrocardiogram was recorded in four of the five patients including the one with the ventricular arrhythmia. After discharge from hospital, ventricular tachycardia that responded to antiarrhythmic drug treatment developed in a sixth patient with a normal signal averaged electrocardiogram.

\section{Discussion}

INCIDENCE AND TIME COURSE OF ABNORMAL SIGNAL AVERAGED ELECTROCARDIOGRAM IN THE POST-INFARCTION PERIOD

The reported incidence of an abnormal signal averaged electrocardiogram in the post-infarction period varied widely in different studies. ${ }^{912} 14$ This could be because of: $(a)$ differences in the recording technique and in the definition of an abnormal recording; (b) the time of the recording in the postinfarction period; and $(c)$ the difference in the incidence of late potentials between anterior and inferior infarctions.

The present study emphasises the importance of the time of recording of the signal averaged electrocardiogram in the post-infarction period. The dynamic nature of abnormalities in the signal averaged electrocardiogram shows the limitations of investigations based on a single recording in the postinfarction period. The present study suggests that the optimal time for signal averaging is between six and 30 days after infarction, rather than in the first five days. When the recording is obtained for the first time during the second month after infarction a significant number of abnormalities will be missed. Late potentials may behave in an even more dynamic way than that shown in the present study. In a preliminary report from our laboratory, serial signal averages were obtained from ambulatory electrocardiograms. ${ }^{18}$ Some patients showed variations of the signal averaged electrocardiographic variables with a 24 hour period. The prognostic significance of transient and more lasting abnormalities in the signal averaged electrocardiogram has yet to be established.

CORRELATION BETWEEN THE ABNORMAL SIGNAL AVERAGED ELECTROCARDIOGRAM AND COMPLEX VENTRICULAR ARRHYTHMIAS

The correlation between an abnormal signal averaged electrocardiogram and complex ventricular arrhythmias from serial recordings in the postinfarction period has not been examined before. Several studies have analysed the relation of a single recording of the signal averaged electrocardiogram to complex ventricular arrhythmias detected by telemetry or the ambulatory electrocardiographic recording or both. In one study, the incidence of high grade ventricular ectopy (Lown grade III to V) was similar in post-infarction patients with or without an abnormal signal averaged electrocardiogram, while non-sustained ventricular tachycardia was slightly more common in the group with a normal recording. ${ }^{14}$ In a previous study from our laboratory an abnormal signal averaged electrocardiogram was more frequent in patients with complex ventricular arrhythmias than in those without. ${ }^{13}$ Differences in method may account for the apparent discrepancy between the previous study and the present report. In the earlier study, no attempt was made to separate early and late complex ventricular arrhythmias or to synchronise electrocardiographic and signal averaged recordings.

The lack of correlation between an abnormal signal averaged electrocardiogram and complex ventricular arrhythmias detected on the ambulatory electrocardiogram may be explained by differences in the electrophysiological bases for the two phenomena. Late potentials represent ischaemic myocardial zones with delayed activation that can provide the electrophysiological basis for re-entrant rhythms. ${ }^{19}$ On the other hand, the underlying electrophysiological mechanism(s) for complex ventricular arrhythmias in the ambulatory electrocardiogram may include reentry and abnormal or triggered automaticity. Complex ventricular arrhythmias caused by focal pacemaker discharge rather than re- 
entry are not expected to be associated with late potentials. Moreover, ventricular tachycardia of non-reentrant origin may occur in a heart showing late potentials and does not have a cause and effect relation with the late potentials.

\section{CLINICAL IMPLICATIONS}

The present study was not designed to determine the long term prognostic significance of the signal averaged electrocardiogram and the ambulatory electrocardiogram in the post-infarction period. None the less, the study suggests that abnormalities in the signal averaged electrocardiograms and complex ventricular arrhythmias in the post-infarction period are independent phenomena and may reflect different electrophysiological conditions. This raises the possibility that the combined use of both noninvasive techniques could provide a better risk stratification for predicting serious arrhythmic events. The optimal time for the recordings and the best technique for recording and analysing the signal averaged electrocardiogram are two issues that need further investigation.

This study was supported by a National Institutes of Health Grant.

\section{References}

1 Marchlinski FE, Buxton AE, Waxman HL, Josephson ME. Identifying patients at risk of sudden death after myocardial infarction: value of the response to programmed stimulation, degree of ventricular ectopic activity and severity of left ventricular dysfunction. Am J Cardiol 1983;52:1190-6.

2 Bigger JT Jr, Fleiss JL, Kleiger K, Miller JP, Rolnitzky LM, and the Multicenter Post-Infarction Research Group. The relationships among ventricular arrhythmias, left ventricular dysfunction, and mortality in the 2 yers after myocardial infarction. Circulation 1984;69:250-8.

3 Mukharji J, Rude RE, Poole WK, et al. Risk factors for sudden death after acute myocardial infarction: two-year follow-up. Am J Cardiol 1984;54:31-6.

4 Morris KG, Palmeri ST, Califf RM, et al. Value of radionuclide angiography for predicting specific cardiac events after acute myocardial infarction. Am J Cardiol 1985;55:318-24.

5 Ruberman W, Weinblatt E, Goldberg JD, Frank CW, Shapiro $S$. Ventricular premature beats and mortality after myocardial infarction. $N$ Engl $J$ Med 1977;297:750-7.

6 Moss AJ, Davies HT, DeCamilla J, Bayer LW. Ventricular ectopic beats and their relation to sudden and nonsudden cardiac death after myocrdial infarction. Circulation 1979;60:998-1003.

7 Bigger JT Jr, Fleiss JL, Rolnitzky LM, and the Multicenter Post-Infarction Research Group. Prevalence, characteristics and significance of ventricular tachycardia detected by 24-hour continuous electrocardiographic recordings in the late hospital phase of acute myocardial infarction. Am J Cardiol 1986;58:1151-60.

8 Waspe LE, Seinfeld D, Ferrick A, Kim SG, Matos JA, Fisher JD. Prediction of sudden death and spontaneous ventricular arrhythmias in survivors of complicated myocardial infarction: value of the response to programmed stimulation using a maximum of three ventricular extrastimuli. J Am Coll Cardiol 1985;5:1292-301.

9 Denniss AR, Richards DA, Cody DV, et al. Prognostic significance of ventricular tachycardia and fibrillation induced at programmed stimulation and delayed potentials detected on the signal-averaged electrocardiograms of survivors of acute myocardial infarction. Circulation 1986;74:731-5.

10 Roy D, Marchand E, Theroux P, et al. Long-term reproducibility and significance of provokable ventricular arrhythmias after myocardial infarction. J Am Coll Cardiol 1986;8:32-9.

11 Breithardt G, Borggrefe M, Haerten K. Ventricular late potentials and inducible ventricular tachyarrhythmias as a marker for ventricular tachycardia after myocardial infarction. Eur Heart $J$ 1986;7 (Suppl A): 127-34.

12 Breithardt G, Schwarzmayer J, Borggrefe $M$, Haerten K, Seipel L. Prognostic signficance of late ventricular potentials after acute myocardial infarction. Eur Heart $J$ 1983;4:487-95.

13 Gomes JA, Mehra R, Barreca P, El-Sherif N, Hariman $R$, Holtzman R. Quantitative analysis of the highfrequency components of the signal-averaged $Q R S$ complex in patients with acute myocardial infarction: a prospective study. Circulation 1985;72:105-11.

14 Kuchar DL, Thorburn CW, Sammel NL. Late potentials detected after myocardial infarction: natural history and prognostic significance. Circulation 1986;74:1280-9.

15 Greenspan AM. Can electrophysiologic testing predict mortality after myocardial infarction? J Am Coll Cardiol 1986;7:1243-4.

16 Simson MB. Use of signals in the terminal QRS complex to identify patients with ventricular tachycardia after myocardial infarction. Circulation $1981 ; 64: 235-42$.

17 Armitage P. Statistical methods in medical research. Oxford: Blackwell Scientific Publications, 1971:13140.

18 Kelen GJ, Henkin R, Howard M, Ferraro C, El-Sherif $N$. Serial signal averages from Holter tapes may reveal intermittent or changing late potentials [Abstract]. $P A C E$ 1987;10:450.

19 El-Sherif N, Gomes JAC, Restivo M, Mehra R. Late potentials and arrhythmogenesis. $P A C E$ 1985;8:44062. 